ISSUES AND INNOVATIONS IN NURSING PRACTICE

\title{
From hospital to home care: a randomized controlled trial of a Pain Education Programme for cancer patients with chronic pain
}

\author{
Rianne de Wit PhD \\ Health Scientist, and Head Pain Expertise Center, Pain Expertise Center, University Hospital Rotterdam, and \\ Department of Medical Psychology and Psychotherapy, Erasmus University, Rotterdam, The Netherlands \\ Previously at the Division of Psychosocial Research and Epidemiology, The Netherlands Cancer Institute/Antoni van \\ Leeuwenhoek Hospital, Amsterdam \\ and Frits van Dam PhD \\ Professor in Medical Psychology, Division of Psychosocial Research and Epidemiology, The Netherlands Cancer Institutel \\ Antoni van Leeuwenhoek Hospital, Amsterdam, The Netherlands and Department of Clinical Psychology, Faculty of \\ Psychology, University of Amsterdam, Amsterdam, The Netherlands
}

Submitted for publication 13 June 2001

Accepted for publication 1 October 2001

Correspondence:

Rianne de Wit,

University Hospital Rotterdam,

Pain Expertise Center-Dijkzigt Hospital,

Dr Molewaterplein 40,

3015 GD Rotterdam,

The Netherlands.

E-mail:dewit@pijn.azr.nl
DE WIT R. \& VAN DAM F. (2001) Journal of Advanced Nursing 36(6), 742-754 From hospital to home care: a randomized controlled trial of a Pain Education Programme for cancer patients with chronic pain

Aim of the study. To investigate the role of district nurses in the care of cancer patients with chronic pain at home, as well as the effects of a Pain Education Programme for patients and their district nurses. The Pain Education Programme consisted of a tailored multi-method approach in which they were educated about pain, instructed how to report pain, and how to contact health care providers.

Background. No educational programs for patients in pain have been studied in outpatients nor integrated with the home care provided.

Design and methods. One hundred and four patients and their 115 district nurses were enrolled in a prospective, longitudinal, randomized controlled study. The primary outcome of interest was type of care provided by district nurses, satisfaction with the pain treatment, and agreement in estimating patients' pain intensity.

Results. Results showed that continuity of care was poor as only $36 \%$ of the district nurses were informed about patients' pain by hospital nurses. Pain was rarely the reason for referring the patient to district nursing after discharge. Although pain control was not a main reason for district nurses to visit a patient, pain was a subject for discussion in $76 \%$ of visits. Besides discussing the pain problem with patients, district nurses provided only a few pain-relieving interventions. District nurses randomized to the intervention group significantly better estimated patients' pain intensity, and were more satisfied about patients' pain treatment, but no differences were found in their assessment of patients' pain relief.

Conclusions. These findings suggest a significant but moderate effect of the Pain Education Programme, with district nurses only playing a minor role in the treatment of cancer pain.

Keywords: pain education, patients' perspective, district nurses, chronic cancer pain, home care, The Netherlands 


\section{Introduction}

Pain is a major symptom for cancer patients in an advanced stage of their disease. It is estimated that approximately $60-80 \%$ of cancer patients in an advanced stage of their disease suffer from pain (Brescia et al. 1992, Higginson \& Hearn 1997). At a time when the average period of hospitalization is decreasing and emphasis has shifted from hospital to home care (Maloney \& Preston 1992), cancer has become a disease with emphasis placed on outpatient care. As a result, pain treatment may be initiated in the hospital or outpatient clinic, while continuation of treatment in the home is primarily carried out by the patient, family and health care professionals.

Pain control in the home situation, however, is more complicated than in the hospital for a number of reasons. First, communication between the different health care providers and the patient, coordination of the care, and continuity of care are often inadequate (Courtens 1993), resulting in fragmented health care (Philipsen \& Stevens 1997). Second, pain is not monitored systematically, and patient self-report of pain is infrequently used. Significant differences between caregivers' observations and patients' self-reports of pain make it difficult to determine the exact course of patients' pain complaints and the efficacy of pain treatment (Holmes \& Eburn 1989, Grossman et al. 1991, Au et al. 1994, Carpenter \& Brockopp 1995). A third obstacle to adequate pain treatment is patients' lack of knowledge, fear of drug tolerance, concerns about side-effects and fear of drug addiction (Levin et al. 1985, Ferrell et al. 1992, Ward et al. 1993, Ferrell et al. 1994). This often results in nonadherence to the pain medication. Dorrepaal (1989) reported that $40 \%$ of cancer outpatients using analgesics did not adhere to the pain medication prescription.

In the Netherlands, health care has a strong emphasis on primary care, which can include the general practitioner, community nurses and home help. Primary care is highly accessible, covered by compulsory or private insurance, and requires no or minimal financial contributions (Schrijvers 1997, Van der Zee et al. 1994). Authorization from a physician is not needed to use community nursing services in the Netherlands, but the general practitioner functions as a 'gatekeeper' for most community and institutional services. District nursing is usually offered to patients who are not able to care for themselves. Although responsibility for the coordination of care formally belongs to the physician or general practitioner, nurses play a prominent role in assessing pain, observing symptoms and reactions, carrying out pain relief methods and educating patients (Mccaffery 1989). In primary care, the district nurses' role has become even more important, because they have an important signalling task with regard to monitoring patients' pain experience and the efficacy of pain treatment; they carry out pharmacological and non-pharmacological pain treatment, identify the need for change in pain management, educate and inform patients, and evaluate the effectiveness of the pain treatment given. Furthermore, an important task of district nurses is to coordinate the primary care.

Up to now, research on the management of cancer pain has mainly been in the inpatient setting. Empirical studies on the quality of care by district nurses in the home setting, as well as their role in pain relief, are scarce (Khalifa 1993, Goodman et al. 1998). Smets (1989) found that nurses consider themselves as playing a minor role in the pain management of cancer patients; most were unable to relieve patients' pain, and rarely contacted physicians or general practitioners about patients' pain. De Schepper et al. (1997) found that Dutch community nurses feel powerless with regard to pain management. Powerlessness was primarily caused by problems in communication between caregivers, dilemmas concerning physical care, and discrepancies between nurses' goals and what can be achieved realistically.

In recent years, several educational programs for patients in pain have been shown to be efficacious. Informing patients about pain and pain treatment by means of written pain information packages and audiotapes is usually a major element of such education programs. Other elements are instructing patients how to self-monitor pain, teaching them how to use non-pharmacological pain management techniques (for example cold, heat, relaxation, massage), teaching communication skills to improve communication about pain experiences with health care providers, and counselling patients about how to cope with the pain. With the exception of one study (Desbiens et al. 1998), all pain education programs (Dalton 1987, Rimer et al. 1987, Rimer et al. 1992, Ferrell et al. 1993, Ferrell et al. 1994, Dalton \& Lambe 1995) have shown to be efficacious on one or more of the following outcome measures: pain intensity, compliance, patients' attitudes regarding addiction, tolerance, side-effects and the use of pain relief methods. However, such programs have neither been studied in outpatients nor integrated with home care (Dalton 1987, Rimer et al. 1987, Rimer et al. 1992, Ferrell et al. 1993, Rhiner et al. 1993, Ferrell et al. 1994, Dalton \& Lambe 1995, Desbiens et al. 1998, Clotfelter 1999).

Pain management in the home situation can only be of high quality if patients and their caregivers are assisted by adequate discharge planning (Yost et al. 1993, Smeenk 1998). Thus, good continuity of care is a prerequisite for 
effective pain management, but this is lacking in the current situation. In the present study, the effectiveness of a 'Pain Education Program' for cancer patients in chronic pain is evaluated, as well as the role of district nurses in the treatment of patients' pain at home. The Pain Education Programme consists of two parts: a programme for patients and their district nurses. The Pain Education Programme for patients consists of three components: enhancing patients' knowledge about pain and pain treatment, instructing them in how to register their pain intensity in a pain diary in the home setting, and stimulating help-seeking behaviour. In the hospital, specially trained nurses educated patients about pain and pain treatment. In addition to the Pain Education Programme for patients, the second part of the intervention consisted of informing district nurses about the pain education programme that patients received. By informing district nurses about patients' pain treatment, the purpose of the Pain Education Programme was to improve their knowledge and understanding regarding patients' pain experience, to enhance their involvement in the pain treatment, and to ensure optimal continuity of care.

\section{The study}

In this study, it was hypothesized that: (1) the Pain Education Programme would result in more communication between health care providers about patients' pain; (2) the level of agreement between nurses' estimations of patients' pain and patients' pain intensity would be improved in the intervention group; and (3) the Pain Education Programme would lead to increased satisfaction with pain treatment and pain relief on the part of the district nurse; (3) the Pain Education Programme would lead to an increased number of pain relieving interventions used by district nurses.

\section{Methods}

\section{Design and subjects}

A randomised, longitudinal study using a pre-test-post-test experimental design was conducted. The Netherlands cancer institute/antoni van Leeuwenhoek hospital, a 180-bed cancer centre in the western part of the Netherlands, was chosen as the coordinating centre. The study was approved by the ethics committee of this hospital. Patients were included in the study if they were admitted to the hospital and were: (1) in pain for at least 1 month; (2) experiencing pain related to cancer, cancer therapy, or illness; (3) expected to live for at least 3 months as assessed by the clinician; (4) able to read and speak dutch; (5) accessible by telephone; and (6) not residing in a nursing home or retirement home.
Prior to randomization, patients were stratified for gender (male/female), age ( $<60$ years/ $\geq 60$ years), and metastatic sites (yes/no/unknown). Those who gave oral informed consent were divided in two groups: patients with and without district nursing in the home setting. In the present study, only results of patients for whom district nursing was organized are reported. Patients were randomly assigned either to the control group, in which regular pain treatment was provided, or the intervention group in which, in addition to the usual pain treatment, the Pain Education Programme was provided. Patients were randomised by an independent trial office by means of a computer.

The Pain Education Programme was started in the hospital. Patients were called at home at three and seven days postdischarge by the same nurse to determine whether the pain information and instruction provided in the hospital was fully understood, and to offer the opportunity to ask questions.

In addition to the Pain Education Programme provided for patients, district nurses taking care of participating patients were asked to participate in the study. District nurses of intervention group patients received additional information about patients' pain complaints by telephone and by means of a written summary. Those of control group patients received no additional information and instruction.

For all patients, data were collected at baseline by means of structured interviews about demographic and medical characteristics, pain experience and pain treatment, as well as quality of life. A follow-up structured interview was arranged at 2, 4, and 8 weeks post-discharge. Participating district nurses were asked about their sociodemographic data by means of a self-report questionnaire, and at 2, 4, and 8 weeks post-discharge of their patients. Patients and district nurses were interviewed individually.

\section{The Pain Education Programme}

The Pain Education Programme was developed on the basis of published reports, existing educational programs, and input of pain experts (NVBP 1990, Spross et al. 1990a, Spross et al. 1990b, World Health Organization (WHO) 1990, American Pain Society (APS) 1992). Three nurses were specially trained as pain counsellors to educate patients about pain and pain treatment. The Pain Education Programme included the use of multiple teaching methods, which were provided both in the hospital and post-discharge by telephone.

The pain education programme for patients consisted of pain information and instruction that was tailored to the needs and abilities of the individual patient. The purposes of the pain education programme for patients were: (1) to improve knowledge of their pain and pain treatment; (2) to 
enhance motivation to adhere to the drug regimen; (3) to monitor pain daily by means of a pain diary; and (4) to stimulate help-seeking behaviour. Topics discussed included: the definition of pain, pharmacological pain management, side-effects, myths and misconceptions related to pain management, non-adherence, use of non-pharmacological pain treatment and pain assessment. The verbal instruction, which was provided in the hospital, was audiotaped on a cassette so that it could be listened to at home. The verbal instruction was accompanied by a pain brochure and diary in which they were instructed how to self-report pain. Finally, patients were instructed how to communicate about pain, when to contact health care providers, and how to use simple non-pharmacological pain management techniques, such as cold, heat, relaxation and massage. To identify whether all information was understood by patients, and to assess whether they were able to complete the pain diary, they were called at three and seven days post-discharge. District nurses of intervention group patients received information about patients' pain complaints, what pain knowledge was lacking, the extent of patients' medication adherence, and how patients' had been taught to monitor pain in a pain diary. District nurses received this information both by telephone and by means of a written summary.

\section{Measures}

\section{District nurses}

Data were collected through self-report questionnaires, structured interviews and nursing records. District nurses were interviewed about their sociodemographic data (Gender, age, years in nursing and educational background). They were also interviewed regarding nursing care provided; reason for being referred to district nursing, type of nursing care provided, pain interventions applied, frequency of visits, frequency in contacting other health care providers and referrals to other primary care services.

Nurses estimation of patients' pain intensity was assessed by means of an 11-point numeric rating scale, on which ' 0 ' represents 'no pain' and '10' represents 'pain as bad as you can imagine'. Reliability of the numeric rating scale is well established (Jensen et al. 1986, Mcguire 1988).

Nurses' satisfaction with the pain treatment, which is indicated as one of the criteria by the American Pain Society to evaluate pain treatment (APS 1992, APS 1995), and the Agency for Health Care Policy and Research (Agency for Health Care Policy and Research (AHCPR) 1994) was measured on a 5-point scale: very satisfied (1), somewhat satisfied (2), neither satisfied nor dissatisfied (3), somewhat dissatisfied (4) and very dissatisfied (5).
Nurses' assessment of patients' pain relief was assessed on a 6-point scale: complete relief (1), strong relief (2), moderate relief (3), slight relief (4), no relief (5) and worsening of pain (6) (Cleeland 1991).

\section{Patients}

Patients were interviewed about demographic variables (Gender, age, and education), medical data (Cancer type, disease stage, and cancer treatment), and pain experience (Pain location, time since onset). Quality of life was measured by means of the EORTC QLQ-C30 $(+3)$ (Aaronson et al. 1993). This quality of life questionnaire contains: (1) five functioning scales (physical functioning, role functioning, emotional functioning, cognitive functioning, and social functioning); (2) three physical symptom scales (fatigue and malaise, nausea and vomiting, pain); (3) several single-item symptom measures (constipation, dyspnea, difficulty with sleeping, appetite loss, diarrhoea, and financial impact); (4) overall perceived health status; and (5) global quality of life.

Patients' pain intensity, satisfaction with pain treatment, and pain relief were assessed in the same way as for district nurses, who were asked to assess pain intensity, satisfaction with the pain treatment, and pain relief.

Finally, pain treatment was reported by means of the threestep who analgesic ladder, consisting of: non-opioid analgesics (Step I), weak opioids with or without non-opioids (Step II), and strong opioids with or without non-opioids (Step III) (WHO 1986).

\section{Statistical analyses}

Data were analysed using the statistical package for the social sciences (SPSS). Descriptive statistics were used to evaluate patients' characteristics. Differences between the control and intervention groups regarding sociodemographic, medical, and pain characteristics were analysed using student's $t$-test for unpaired observations, chi-square, and non-parametric tests. Comparability between groups regarding quality of life was analysed by means of $t$-tests. To evaluate the effect of the pain education programme and changes over time, student's $t$-tests and multivariate analyses of variance (MANOVA) were conducted. To compare different pain intensity scores, Pearson correlation coefficients were used. Comparability of control and intervention groups for agreement between patients' pain intensity and nurses' estimation of patients' pain were analysed dichotomously by chi-square tests. Difference regarding satisfaction with pain treatment and pain relief were analysed by means of student's $t$-test. A $P$-value of $<0.05$ (two-tailed) was considered significant. 


\section{Results}

\section{Sample demographics}

A total of 383 patients meeting the inclusion criteria were invited to participate in the study, and of these 70 patients $(18 \%)$ declined. Reasons for declining were: study was too burdensome $(n=48 ; 69 \%)$, not motivated $(n=15 ; 21 \%)$, or too ill $(n=7 ; 10 \%)$. The remaining 313 patients consisted of 104 who needed district nursing at home. Here, we report on these 104 patients, and on the district nurses caring for them. After randomization, 51 patients were in the control group and 53 in the intervention group. The sample size decreased to $83(80 \%)$ at week 2, $76(73 \%)$ at week 4 , and $72(69 \%)$ at week 8 , because of deaths $(67 \%)$, being too ill $(24 \%)$, and experiencing the study as too burdensome $(9 \%)$. The dropout rate in the intervention group was significantly higher than in the control group at week $4(P=0.01)$, and week 8 $(P<0.05)$. At week 8 , the dropout rate in the intervention group was $41 \%$ compared with $20 \%$ in the control group. This was mainly because of the high percentage of patients who died during follow-up.

In total, 115 district nurses were taking care of the 104 participating patients. All district nurses agreed to participate in the study. Overall, data were collected on 110 nurses. In five patients, no district nurse provided care, because the patient died before discharge or was readmitted to hospital

Table 1 Demographic data on district nurses participating in the pain education program

\begin{tabular}{|c|c|c|}
\hline & $n$ & $\%$ \\
\hline \multicolumn{3}{|l|}{ Gender } \\
\hline Female & 102 & 93 \\
\hline \multirow[t]{2}{*}{ Male } & 8 & 7 \\
\hline & Mean & SD \\
\hline Age (years) $(n=110)$ & $37 \cdot 4$ & $9 \cdot 9$ \\
\hline $\begin{array}{l}\text { Years of professional nursing experience } \\
\text { (years) }(n=110)\end{array}$ & $15 \cdot 4$ & $10 \cdot 1$ \\
\hline \multirow[t]{2}{*}{ Hours of work per week (years) $(n=110)$} & $31 \cdot 2$ & $5 \cdot 9$ \\
\hline & $n$ & $\%$ \\
\hline \multicolumn{3}{|l|}{ Educational level } \\
\hline District nurse & 100 & $87 \cdot 0$ \\
\hline Registered nurse & 3 & $2 \cdot 6$ \\
\hline Practical nurse & 7 & $6 \cdot 1$ \\
\hline $\begin{array}{l}\text { Missing (no care was provided by a district } \\
\text { nurses because, for example, patient died } \\
\text { in the hospital or was readmitted) }\end{array}$ & 5 & $4 \cdot 3$ \\
\hline
\end{tabular}

immediately. For 22 patients, more than one district nurse was interviewed about their care. Demographic data of the nurses are given in Table 1 . The majority were female (93\%), the mean age was 37 years $(\mathrm{SD}=10)$, and the mean professional nursing experience was $15 \cdot 4$ years $(\mathrm{SD}=10)$. Thirtyfive percent of patients received home care services in addition to district nursing.

Patient characteristics are described in Table 2. Of the 104 patients, there were 32 males ( $31 \%)$ and 72 females $(69 \%)$ and they ranged in age from 21 to 79 years $(\mathrm{SD}=13)$. The most common diagnoses were breast and genitourinary cancer. No differences were found between the control and intervention group for sociodemographic and medical parameters, except that patients in the intervention group were prescribed more analgesics than those in the control group $(P<0.001)$.

At pre-test, the mean score for patients' present pain intensity was $3.4(\mathrm{SD}=2.5)$. Patients' average pain intensity during the previous week was $5 \cdot 1(\mathrm{SD}=2 \cdot 2)$, and patient's worst pain intensity was $8 \cdot 0(\mathrm{SD}=2 \cdot 2)$. No differences were found between the groups (Table 3).

To determine patients' quality of life, results of the EORTC QLQ-C30(+3) at baseline and four weeks post-discharge are given in Table 4. Overall, patients showed low values on the different functioning scales of quality of life, especially on physical functioning and role functioning at baseline, despite randomization, patients in the intervention group scored significantly lower on physical functioning $(P=0.05)$ and cognitive functioning $(P<0.05)$ than control group patients. In addition to pain, patients reported a broad spectrum of symptoms, and experienced on average 4.4 symptoms $(\mathrm{SD}=1 \cdot 5)$. Most frequently, they reported fatigue, pain, loss of appetite, sleep disturbance and constipation. At 4 weeks post-discharge, a statistically significant increase in score in the period from baseline to 4 weeks post-discharge (time effect) was found for cognitive functioning $(P<0.001)$ and emotional functioning $(P<0.001)$, indicating that these had improved in all patients. With regard to the symptom scales, patients experienced less pain $(P<0.001)$, sleep disturbance $(P<0.001)$, fatigue $(P=0.01)$, appetite loss $(P<0.001)$, and diarrhoea $(P=0.01)$ at 4 weeks post-discharge as compared with baseline. In addition to a time effect, a statistically significant difference on fatigue over time (time-group interaction) was found between the groups $(P<0 \cdot 05)$, meaning that experimental group patients showed more of a reduction in fatigue over time compared with the control group patients.

\section{Nursing care}

Continuity of care is achieved by providing a link between hospital and district nurses in the home setting. District 
Table 2 Sociodemographic, medical, and pain characteristics of the patients at pre-test

\begin{tabular}{|c|c|c|c|}
\hline & Control group & Intervention group & $P$-value \\
\hline \multicolumn{4}{|l|}{ Gender $(n, \%)$} \\
\hline Male & $16(31 \cdot 4 \%)$ & $16(30 \cdot 2 \%)$ & \multirow[t]{2}{*}{$\mathrm{ns}^{\mathrm{a}}$} \\
\hline Female & $35(68 \cdot 6 \%)$ & $37(69 \cdot 8 \%)$ & \\
\hline Age (mean in years, SD) & $58 \cdot 1(12 \cdot 4)$ & $60 \cdot 5(12 \cdot 9)$ & $\mathrm{ns}^{\mathrm{b}}$ \\
\hline \multicolumn{4}{|l|}{ Education } \\
\hline Low & $22(43 \cdot 1 \%)$ & $20(37 \cdot 7 \%)$ & \multirow[t]{3}{*}{$\mathrm{ns}^{\mathrm{c}}$} \\
\hline Middle & $16(31 \cdot 4 \%)$ & $19(35 \cdot 8 \%)$ & \\
\hline High & $13(25 \cdot 5 \%)$ & $14(26 \cdot 4 \%)$ & \\
\hline \multicolumn{4}{|l|}{ Primary tumour site $(>100 \%)$} \\
\hline Lip, oral cavity, and pharynx & $1(02 \cdot 0 \%)$ & $5(09 \cdot 4 \%)$ & \multirow[t]{7}{*}{$\mathrm{ns}^{\mathrm{c}}$} \\
\hline Digestive organs and peritoneum & $6(11 \cdot 8 \%)$ & $4(07 \cdot 5 \%)$ & \\
\hline Respiratory and intrathoracic organs & $2(03 \cdot 9 \%)$ & $3(05 \cdot 7 \%)$ & \\
\hline Breast & $15(29 \cdot 4 \%)$ & $18(34 \cdot 0 \%)$ & \\
\hline Bone, connective tissue, and skin & $26(11 \cdot 8 \%)$ & $4(07 \cdot 5 \%)$ & \\
\hline Genitourinary organs & $19(37 \cdot 3 \%)$ & $17(32 \cdot 1 \%)$ & \\
\hline Other [i.e. (non-)Hodgkin lymphoma] & $8(15 \cdot 7 \%)$ & $7(13 \cdot 2 \%)$ & \\
\hline \multicolumn{4}{|l|}{ Disease stage } \\
\hline Local & $4(07 \cdot 8 \%)$ & $4(07 \cdot 5 \%)$ & \multirow[t]{4}{*}{$\mathrm{ns}^{\mathrm{c}}$} \\
\hline Regional & $11(21 \cdot 6 \%)$ & $12(22 \cdot 6 \%)$ & \\
\hline Metastatic & $31(60 \cdot 8 \%)$ & $32(60 \cdot 4 \%)$ & \\
\hline Unknown/not applicable & $5(9 \cdot 8 \%)$ & $5(9 \cdot 4 \%)$ & \\
\hline \multicolumn{3}{|l|}{ Treatment $(>100 \%)$} & \multirow[t]{7}{*}{$\mathrm{ns}^{\mathrm{c}}$} \\
\hline No & $10(19 \cdot 6 \%)$ & $14(26 \cdot 4 \%)$ & \\
\hline Surgery & $11(21 \cdot 6 \%)$ & $6(11 \cdot 3 \%)$ & \\
\hline Chemotherapy & $14(27 \cdot 5 \%)$ & $9(17 \cdot 0 \%)$ & \\
\hline Radiation therapy & $9(17 \cdot 6 \%)$ & $12(22 \cdot 6 \%)$ & \\
\hline Hormonal therapy & $5(09 \cdot 8 \%)$ & $7(13 \cdot 2 \%)$ & \\
\hline Other (i.e. hormonal, immuno, laser) & $02(03 \cdot 9 \%)$ & $05(09 \cdot 4 \%)$ & \\
\hline Pain duration (mean in months, SD) & $9 \cdot 9(13 \cdot 5)$ & $8 \cdot 2(13 \cdot 6)$ & $n s^{b}$ \\
\hline \multicolumn{4}{|l|}{ Pain location $(>100 \%)$} \\
\hline Head, face, mouth, cervical region & $8(15 \cdot 7 \%)$ & $12(22 \cdot 6 \%)$ & \multirow[t]{7}{*}{$\mathrm{ns}^{\mathrm{c}}$} \\
\hline Breast, thoracic region & $12(39 \cdot 2 \%)$ & $9(17 \cdot 0 \%)$ & \\
\hline Upper shoulder, and upper limbs & $10(19 \cdot 6 \%)$ & $16(30 \cdot 2 \%)$ & \\
\hline Abdominal region & $21(41 \cdot 2 \%)$ & $22(41 \cdot 5 \%)$ & \\
\hline Lower back, lumbar spine, sacrum & $23(45 \cdot 1 \%)$ & $21(39 \cdot 6 \%)$ & \\
\hline Lower limbs & $18(35 \cdot 3 \%)$ & $13(24 \cdot 5 \%)$ & \\
\hline Anal, perineal, and genital region & $5(09 \cdot 8 \%)$ & $2(03 \cdot 8 \%)$ & \\
\hline \multicolumn{4}{|l|}{ Pain cause } \\
\hline Tumour involvement & $36(70 \cdot 6 \%)$ & $36(67 \cdot 9 \%)$ & \multirow[t]{5}{*}{$\mathrm{ns}^{\mathrm{c}}$} \\
\hline Cancer therapy & $4(07 \cdot 8 \%)$ & $3(05 \cdot 7 \%)$ & \\
\hline Tumor involvement and cancer therapy & $5(09 \cdot 8 \%)$ & $5(09 \cdot 4 \%)$ & \\
\hline Related to disease or debility & $4(07 \cdot 8 \%)$ & $7(13 \cdot 2 \%)$ & \\
\hline Unknown & $2(03 \cdot 9 \%)$ & $2(3 \cdot 8 \%)$ & \\
\hline Analgesics & $42(82 \cdot 4 \%)$ & $52(98 \cdot 1 \%)$ & $<0 \cdot 001^{\mathrm{a}}$ \\
\hline
\end{tabular}

${ }^{\mathrm{a} C h i}$-square; 'btudent's $t$-tests; 'Non-parametric tests (McNemar tests); ns: not significant, $P>0.05$; two-tailed.

nurses were asked about the extent to which they were informed by hospital nurses about patients' pain complaints. Results showed that only $36 \%$ were informed by hospital nurses about any aspect of patients' pain before discharge.
There was no difference between control and intervention group patients in the extent of information provided. The severity of patients' pain intensity was not related to informing district nurses patients about this. 


\begin{tabular}{llllll}
\hline & $\begin{array}{l}\text { Control group } \\
\text { mean (SD) }\end{array}$ & $\begin{array}{l}\text { Intervention group } \\
\text { mean (SD) }\end{array}$ & $\begin{array}{l}\text { Total } \\
\text { mean (SD) }\end{array}$ & $n$ & $P$-value \\
\hline Present Pain Intensity & $3 \cdot 7(2 \cdot 6)$ & $3 \cdot 2(2 \cdot 4)$ & $3 \cdot 4(2 \cdot 5)$ & 103 & $\mathrm{~ns}^{\mathrm{b}}$ \\
Average Pain Intensity & $5 \cdot 4(2 \cdot 1)$ & $4 \cdot 8(2 \cdot 2)$ & $5 \cdot 1(2 \cdot 2)$ & 100 & $\mathrm{~ns}$ \\
Worst Pain Intensity & $8 \cdot 0(2 \cdot 9)$ & $8 \cdot 0(2 \cdot 0)$ & $8 \cdot 0(2 \cdot 0)$ & 102 & $\mathrm{~ns}$ \\
\hline
\end{tabular}

${ }^{a}$ Student's $t$-tests; ${ }^{b}$ not significant.

After discharge, patients were visited by district nurses on average nine times during the first 2 weeks $(\mathrm{SD}=8$; range $0-42)$. The number of visits remained stable over a 2-month period; no differences were found between the groups (Table 5). At 2 weeks post-discharge, $30 \%$ of the district nurses had not contacted another health care provider in the previous 2 weeks, $39 \%$ had contacted a colleague, $26 \%$ had contacted a general practitioner, and $6 \%$ had contacted another health care provider. No differences were found between the control and intervention groups.

The most important reasons for home visits mentioned by district nurses were: moral support $(58 \%)$, hygienic care or technical nursing care $(48 \%)$, wound care or dressings $(23 \%)$, health education $(20 \%)$, observation $(11 \%)$, medication administration $(8 \%)$ and miscellaneous $(9 \%)$. Pain was hardly mentioned as the main reason for the provision of services by district nurses. The main reasons for visiting the patient remained stable over time, with moral support as the most frequently mentioned type of care provided. No significant differences were found between control and intervention patients.

District nurses were also asked what two most important services were provided regarding patients' pain control. Results are given in Table 6. Although pain control was not the main reason for visiting patients at home, it was a subject for discussion for the majority of patients $(76 \%)$. Furthermore, the use of pain medication was discussed in $36 \%$ of patients, and information on side-effects was provided in $21 \%$ at two weeks after discharge. No significant differences were found between control and intervention patients. It is striking that nurses most frequently discussed the pain problem with the patient. Interventions that form an important foundation in pain treatment, such as Non-pharmacological pain interventions (Heat, cold, massage, relaxation, and distraction), cognitive interventions (Attention-diversion, instructions for self-care, structured educational programs, and support in coping), behavioural interventions (Family counselling, and self-monitoring pain), and affective intervention (Reduction of anxiety, anger, guilt, and depression) were rarely mentioned by district nurses.
Table 3 Patients' pain intensity at baseline

\section{Effects of pain education programme}

Overall, district nurses were positive about the additional information and instruction received by means of the pain education programme: $94 \%$ evaluated the pain education programme for district nurses as (very) good at week 4 , and $93 \%$ at week 8 . In addition, $87 \%$ of the district nurses evaluated the pain education programme for patients as (very) good at week 4 , and $50 \%$ at week 8 . In only one patient, the additional pain information was evaluated as bad.

The effectiveness of the pain education programme was evaluated by district nurses as (very) good in $45 \%$, not good/ not bad in $32 \%$, bad in $3 \%$, and $19 \%$ did not have an opinion at week 4 . Their opinions remained stable over time as $50 \%$ evaluated the effect of the pain education programme as (very) good at week 8 .

Agreement between patients' and nurses' estimations of pain intensity was evaluated in the intervention and control group. Agreement was defined as a nurse's estimation of patient's pain that was equal to or within a range of 1 on a scale from 0 to 10 with patient's pain intensity. Nonagreement was defined as a discrepancy of two or more between nurse's estimation of patient's pain and patient's pain score. Overall, the Pearson correlations between patient's pain intensity scores and nurses' estimation of patients' pain was $r=0.44$ at 2 weeks, $r=0.54$ at 4 weeks, and $r=0.53$ at 8 weeks $(P<0 \cdot 001)$. Nurses accurately assessed patients' pain intensity in $57 \%$ of patients at week 2 , $64 \%$ at week 4 , and $59 \%$ at week 8 . For district nurses who were inaccurate in assessing patients' pain, pain intensity was most frequently overestimated $(72 \%, 68 \%$, and $61 \%$ at week 2,4 , and 8 , respectively).

Results showed that district nurses in the intervention group significantly better estimated patients' pain intensity at 2 weeks post-discharge than in the control group (Figure 1). At week 4 there was a trend for district nurses of patients in the intervention group to better estimate patients' pain than those of patients in the control group. At week 8, there was no significant differences between the groups.

Regarding quality of pain treatment, district nurses were dissatisfied with the pain treatment in only a minority of patients: $21 \%$ at week $2,21 \%$ at week 4 , and $4 \%$ at week 8 . At 
Table 4 Results of the quality of life questionnaire at baseline and 4 weeks post-discharge

\begin{tabular}{|c|c|c|c|c|c|}
\hline & Control group & Intervention group & $P$-value ${ }^{\mathrm{c}}$ & $P$-value ${ }^{\mathrm{d}}$ & $P$-value ${ }^{\mathrm{e}}$ \\
\hline \multicolumn{6}{|l|}{ Functioning scales ${ }^{\mathrm{a}}$} \\
\hline \multicolumn{6}{|l|}{ Physical functioning } \\
\hline Pre-test & $29 \cdot 8(29 \cdot 8)$ & $19 \cdot 2(24 \cdot 8)$ & $P=0.05$ & ns & ns \\
\hline 4 weeks post-discharge ${ }^{\mathrm{d}}$ & $26 \cdot 1(25 \cdot 2)$ & $27 \cdot 7(30 \cdot 4)$ & ns & & \\
\hline \multicolumn{6}{|l|}{ Role functioning } \\
\hline Pre-test & $17 \cdot 6(29 \cdot 1)$ & $13 \cdot 5(21 \cdot 9)$ & ns & ns & ns \\
\hline 4 weeks post-discharge & $19 \cdot 5(25 \cdot 5)$ & $25 \cdot 3(28 \cdot 8)$ & ns & & \\
\hline \multicolumn{6}{|l|}{ Cognitive functioning } \\
\hline Pre-test & $71 \cdot 2(25 \cdot 4)$ & $58 \cdot 8(27 \cdot 1)$ & $P>0.05$ & $P>0.001$ & ns \\
\hline 4 weeks post-discharge & $82.5(23.6)$ & $72 \cdot 6(30 \cdot 0)$ & ns & & \\
\hline \multicolumn{6}{|l|}{ Emotional functioning } \\
\hline Pre-test & $56 \cdot 2(23 \cdot 6)$ & $55 \cdot 0(27 \cdot 3)$ & ns & $P>0.001$ & ns \\
\hline 4 weeks post-discharge & $69 \cdot 1(27 \cdot 3)$ & $67 \cdot 4(24 \cdot 8)$ & ns & & \\
\hline \multicolumn{6}{|l|}{ Social functioning } \\
\hline Pre-test & $52.6(34 \cdot 4)$ & $58 \cdot 5(29 \cdot 7)$ & ns & ns & ns \\
\hline 4 weeks post-discharge & $62 \cdot 1(32 \cdot 2)$ & $65 \cdot 1(33 \cdot 4)$ & ns & & \\
\hline \multicolumn{6}{|l|}{ Global quality of life } \\
\hline Pre-test & $44 \cdot 1(23 \cdot 5)$ & $43 \cdot 1(22 \cdot 0)$ & ns & ns & ns \\
\hline 4 weeks post-discharge & $49 \cdot 4(22 \cdot 2)$ & $51 \cdot 7(21.7)$ & ns & & \\
\hline \multicolumn{6}{|l|}{ Symptom scales and items ${ }^{b}$} \\
\hline \multicolumn{6}{|l|}{ Fatigue } \\
\hline Pre-test & $67 \cdot 5(28 \cdot 8)$ & $77 \cdot 8(25 \cdot 9)$ & ns & $P=0 \cdot 01$ & $P>0.05$ \\
\hline 4 weeks post-discharge & $62 \cdot 2(27 \cdot 4)$ & $59 \cdot 9(29 \cdot 4)$ & ns & & \\
\hline \multicolumn{6}{|l|}{ Nausea and vomiting } \\
\hline Pre-test & $40 \cdot 8(34 \cdot 0)$ & $28.9(33.5)$ & ns & ns & ns \\
\hline 4 weeks post-discharge & $29 \cdot 0(32 \cdot 3)$ & $22 \cdot 6(32 \cdot 4)$ & ns & & \\
\hline \multicolumn{6}{|l|}{ Pain } \\
\hline Pre-test & $75 \cdot 2(28 \cdot 6)$ & $75 \cdot 5(25 \cdot 2)$ & ns & $P>0.001$ & ns \\
\hline 4 weeks post-discharge & $52 \cdot 4(34 \cdot 6)$ & $58 \cdot 6(27 \cdot 5)$ & ns & & \\
\hline \multicolumn{6}{|l|}{ Dyspnea } \\
\hline Pre-test & $26 \cdot 1(36 \cdot 7)$ & $30 \cdot 2(37 \cdot 1)$ & ns & ns & ns \\
\hline 4 weeks post-discharge & $20 \cdot 3(31 \cdot 5)$ & $18 \cdot 8(29 \cdot 3)$ & ns & & \\
\hline \multicolumn{6}{|l|}{ Sleep disturbance } \\
\hline Pre-test & $44 \cdot 4(39 \cdot 3)$ & $40 \cdot 3(43 \cdot 5)$ & ns & $P>0.001$ & ns \\
\hline 4 weeks post-discharge & $27 \cdot 8(38.9)$ & $23 \cdot 7(38 \cdot 7)$ & ns & & \\
\hline \multicolumn{6}{|l|}{ Loss of appetite } \\
\hline Pre-test & $66 \cdot 0(38.6)$ & $65 \cdot 4(36 \cdot 1)$ & ns & $P>0.001$ & ns \\
\hline 4 weeks post-discharge & $46 \cdot 3(42 \cdot 1)$ & $36 \cdot 7(37 \cdot 5)$ & ns & & \\
\hline \multicolumn{6}{|l|}{ Constipation } \\
\hline Pre-test & $40 \cdot 7(40 \cdot 0)$ & $38 \cdot 8(40 \cdot 5)$ & ns & ns & ns \\
\hline 4 weeks post-discharge & $25 \cdot 8(38 \cdot 8)$ & $21 \cdot 5(36 \cdot 1)$ & ns & & \\
\hline \multicolumn{6}{|l|}{ Diarrhoea } \\
\hline Pre-test & $24 \cdot 7(32 \cdot 2)$ & $17 \cdot 0(28 \cdot 2)$ & ns & $P=0 \cdot 01$ & ns \\
\hline 4 weeks post-discharge & $07 \cdot 5(23 \cdot 3)$ & $09 \cdot 7(24 \cdot 6)$ & ns & & \\
\hline \multicolumn{6}{|l|}{ Financial impact } \\
\hline Pre-test & $14 \cdot 0(29 \cdot 4)$ & $14 \cdot 5(28 \cdot 1)$ & ns & ns & ns \\
\hline 4 weeks post-discharge & $14 \cdot 2(26 \cdot 0)$ & $08 \cdot 6(19 \cdot 2)$ & ns & & \\
\hline
\end{tabular}

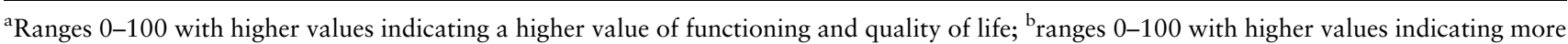
symptoms/difficulties; 'control group vs. Intervention group at baseline and four weeks post-discharge analysed by means of student's $t$-tests; ${ }^{\mathrm{d}}$ time effect analysed by means of student's $t$-tests; ${ }^{\mathrm{e}}$ interaction effect (group $\times$ time) analysed by means of MANOVA. 


\begin{tabular}{lllll}
\hline $\begin{array}{l}\text { Number of contacts with } \\
\text { patient in previous 2 weeks }\end{array}$ & $\begin{array}{l}\text { Control group } \\
\text { Mean (SD) }\end{array}$ & $\begin{array}{l}\text { Intervention group } \\
\text { Mean (SD) }\end{array}$ & $\begin{array}{l}\text { Total } \\
\text { Mean (SD) }\end{array}$ & $P$-value \\
\hline Week 2 & $7 \cdot 4(6 \cdot 6)$ & $9 \cdot 1(6 \cdot 6)$ & $8 \cdot 8(8 \cdot 1)$ & $\mathrm{ns}^{\mathrm{b}}$ \\
Week 4 & $7 \cdot 9(7 \cdot 6)$ & $7 \cdot 6(5 \cdot 6)$ & $7 \cdot 3(6 \cdot 3)$ & $\mathrm{ns}$ \\
Week 8 & $6 \cdot 1(6 \cdot 8)$ & $6 \cdot 8(8 \cdot 4)$ & $7 \cdot 4(8 \cdot 2)$ & $\mathrm{ns}$ \\
\hline
\end{tabular}

Table 5 Contacts with patients at home

${ }^{\text {a }}$ Student's $t$-tests; ${ }^{b}$ not significant.

Table 6 Most important services provided by district nurses

\begin{tabular}{|c|c|c|c|c|}
\hline $\begin{array}{l}\text { Most important } \\
\text { services provided }^{\text {a }}\end{array}$ & $\begin{array}{l}\text { Control } \\
\text { group }(\mathrm{N}(\%))^{\mathrm{b}}\end{array}$ & $\begin{array}{l}\text { Intervention } \\
\text { group }(\mathrm{N}(\%))\end{array}$ & $\begin{array}{l}\text { Total } \\
(\mathrm{N}(\%))\end{array}$ & $P$-value ${ }^{\mathrm{c}}$ \\
\hline \multicolumn{5}{|l|}{ Discuss pain } \\
\hline Week 2 & $22(71)$ & $29(81)$ & $51(76)$ & \multirow[t]{3}{*}{$n s^{c}$} \\
\hline Week 4 & $24(80)$ & $20(67)$ & $44(73)$ & \\
\hline Week 8 & $19(79)$ & $20(74)$ & $39(77)$ & \\
\hline \multicolumn{5}{|c|}{ Discuss use of medication and adherence } \\
\hline Week 2 & $10(32)$ & $14(39)$ & $24(36)$ & \multirow[t]{3}{*}{ ns } \\
\hline Week 4 & $11(37)$ & $9(30)$ & $20(33)$ & \\
\hline Week 8 & $11(46)$ & $8(30)$ & $19(37)$ & \\
\hline \multicolumn{5}{|c|}{ Provide relaxation, massage, etc. } \\
\hline Week 2 & $0(00)$ & $3(08)$ & $3(05)$ & \multirow[t]{3}{*}{ ns } \\
\hline Week 4 & $2(07)$ & $2(07)$ & $4(07)$ & \\
\hline Week 8 & $2(08)$ & $3(11)$ & $5(10)$ & \\
\hline \multicolumn{5}{|c|}{ Provide aids to reduce pain } \\
\hline Week 2 & $6(19)$ & $6(17)$ & $15(18)$ & \multirow[t]{3}{*}{ ns } \\
\hline Week 4 & $3(10)$ & $4(13)$ & $7(12)$ & \\
\hline Week 8 & $2(08)$ & $3(11)$ & $5(10)$ & \\
\hline \multicolumn{5}{|c|}{ Administer analgesics } \\
\hline Week 2 & $0(00)$ & $2(06)$ & $2(03)$ & \multirow[t]{3}{*}{ ns } \\
\hline Week 4 & $1(03)$ & $2(07)$ & $3(05)$ & \\
\hline Week 8 & $0(00)$ & $0(00)$ & $0(00)$ & \\
\hline \multicolumn{5}{|c|}{ Inform about pain and side-effects } \\
\hline Week 2 & $9(29)$ & $5(14)$ & $14(21)$ & \multirow[t]{3}{*}{ ns } \\
\hline Week 4 & $3(10)$ & $9(30)$ & $12(20)$ & \\
\hline Week 8 & $2(08)$ & $4(15)$ & $6(12)$ & \\
\hline \multicolumn{5}{|c|}{ Consult other caregivers } \\
\hline Week 2 & $2(07)$ & $1(03)$ & $3(05)$ & \multirow[t]{3}{*}{ ns } \\
\hline Week 4 & $3(10)$ & $0(00)$ & $3(05)$ & \\
\hline Week 8 & $1(04)$ & $2(07)$ & $3(06)$ & \\
\hline \multicolumn{5}{|l|}{ Reduce anxiety } \\
\hline Week 2 & $1(03)$ & $1(03)$ & $2(03)$ & \multirow[t]{3}{*}{ ns } \\
\hline Week 4 & $2(07)$ & $0(00)$ & $2(03)$ & \\
\hline Week 8 & $1(04)$ & $1(04)$ & $2(04)$ & \\
\hline \multicolumn{5}{|l|}{ Provide wound care } \\
\hline Week 2 & $1(03)$ & $2(06)$ & $3(05)$ & \multirow[t]{3}{*}{ ns } \\
\hline Week 4 & $1(03)$ & $3(10)$ & $4(07)$ & \\
\hline Week 8 & $0(00)$ & $1(04)$ & $1(02)$ & \\
\hline
\end{tabular}

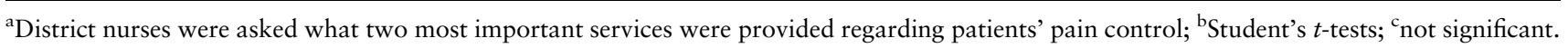




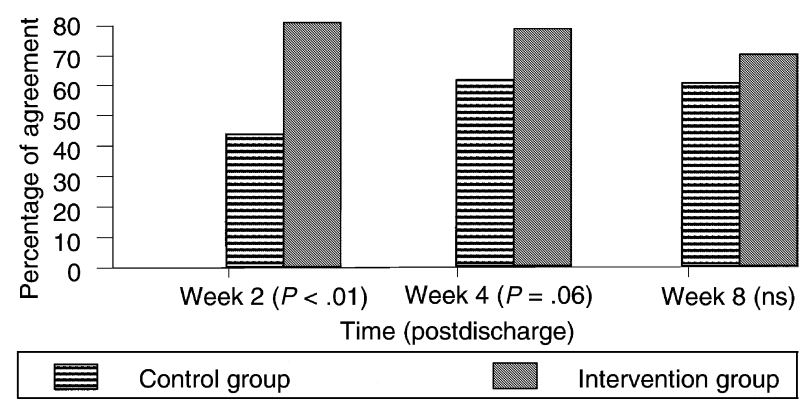

Figure 1 Agreement between patients' pain intensity and nurses' estimation of patients' pain.

all assessment points, district nurses of patients in the intervention group were significantly more satisfied with patients' pain treatment than nurses in the control group (Table 7).

When examining the differences between responses from patients and nurses' perceptions, the exact agreement between the nurse and the patient varied from $15 \%$ to $24 \%$ at the three assessment points. Two weeks after discharge, significantly less difference was found in the intervention group in the estimation of patients' satisfaction with the pain treatment compared with the control group $(P=0.05)$. No differences were found between the control and intervention groups at weeks 4 and 8 .

Nurses were asked to assess patients' relief with the pain treatment. Two weeks after discharge, they reported that $44 \%$ of patients had complete, strong, or moderate relief from the pain treatment. At week 4 and 8 , pain relief was reported by $53 \%$ and $52 \%$, respectively. The exact agreement between what patients reported about the extent of pain relief and how nurses estimated patient's pain relief varied from $19 \%$ to $28 \%$ at the three assessment points. A large discrepancy between patient's pain relief and nurse's estimation of this was found: the discrepancy varied from $39 \%$ to $47 \%$, meaning that nurses frequently assess relief from pain treatment differently compared with patients. No differences in discrepancy between district nurses and patients were found between the groups.

\section{Discussion}

In this study, the role of district nurses in the care of cancer patients with chronic pain at home was investigated, as well as the effect of the pain education program. In total, 104 patients and their 115 district nurses were enrolled in a prospective, longitudinal, randomized controlled study. Both patients and district nurses were followed-up for 2 months post-discharge.

Because advanced cancer patients with pain are often cared for by various health care providers in both hospital and home care settings, coordination and continuity of care are requisites. Results showed that continuity of care was poor, as only $36 \%$ of the district nurses were informed by hospital nurses about patients' pain. This is in agreement with other Dutch studies reporting that coordination between hospital caregivers and primary caregivers was low (Courtens 1993, Smeenk 1998).

Pain was rarely the reason for referral to district nurses. Most frequently, patients were referred for moral support and hygienic or technical nursing care. We were surprised by the result that pain was rarely the main reason for provision of district nursing, considering that most patients experienced moderate to severe pain at home. Nevertheless, district nurses considered patients' pain problems as very important. All district nurses were willing to participate in the study and frequently underlined the importance of adequate pain control. However, besides discussing the pain problem with the patient, results showed that they rarely applied painrelieving interventions.

Evaluation of the pain education programme showed that district nurses were positive about the additional information and instruction received, and evaluated the effectiveness of the pain education programme as good or very good in

Table 7 Nurses' estimation of satisfaction with pain treatment and pain relief

\begin{tabular}{|c|c|c|c|c|}
\hline & $\begin{array}{l}\text { Control group } \\
\text { Mean (SD) }\end{array}$ & $\begin{array}{l}\text { Intervention group } \\
\text { Mean (SD) }\end{array}$ & $\begin{array}{l}\text { Total } \\
\text { Mean (SD) }\end{array}$ & $P$-value ${ }^{\mathrm{a}}$ \\
\hline \multicolumn{5}{|c|}{ Nurses' assessment of satisfaction with pain treatment ${ }^{\mathrm{b}}$} \\
\hline Week 2 & $3 \cdot 5(1.4)$ & $2 \cdot 6(1 \cdot 3)$ & $3 \cdot 0(1 \cdot 4)$ & $<0 \cdot 01$ \\
\hline Week 4 & $3 \cdot 2(1 \cdot 4)$ & $2 \cdot 4(1 \cdot 0)$ & $2 \cdot 8(1 \cdot 3)$ & $<0 \cdot 01$ \\
\hline Week 8 & $3 \cdot 0(1 \cdot 4)$ & $2 \cdot 4(0 \cdot 9)$ & $2 \cdot 7(1 \cdot 2)$ & $<0 \cdot 05$ \\
\hline \multicolumn{5}{|c|}{ Nurses' assessment of patients' pain relief ${ }^{c}$} \\
\hline Week 2 & $4 \cdot 0(1 \cdot 7)$ & $3 \cdot 6(1.4)$ & $3 \cdot 8(1 \cdot 5)$ & $n s^{\mathrm{d}}$ \\
\hline Week 4 & $3 \cdot 9(1 \cdot 7)$ & $3 \cdot 3(1 \cdot 5)$ & $3.6(1.6)$ & ns \\
\hline Week 8 & $3 \cdot 7(1 \cdot 7)$ & $3 \cdot 6(1 \cdot 3)$ & $3 \cdot 7(1 \cdot 5)$ & ns \\
\hline
\end{tabular}

${ }^{a}$ Student's $t$-tests; ${ }^{\mathrm{b}}$ scores range from 1 to 5 , with higher scores indicating less satisfaction with the pain treatment; ${ }^{\mathrm{c}}$ scores range from 1 to 6 , with lower scores indicating more pain relief; ${ }^{\mathrm{d}}$ not significant. 
approximately half of the patients. Furthermore, results showed that district nurses are not well informed about patients' pain. In the control group, more than half could not accurately estimate patients' pain. Although it is often found that nurses have difficulty estimating patients' pain, this result is striking because district nurses visit patients on average once per day or every other day. District nurses who were informed and instructed by means of the pain education programme significantly better estimated patients' pain intensity; however, the differences between control and intervention results decreased over time.

Most district nurses were satisfied with patients' pain treatment, with only approximately $20 \%$ being dissatisfied. Those in the intervention group were more satisfied with patients' pain treatment than those in the control group, and showed less discrepancy with patients in the assessment of satisfaction with pain treatment. Regarding nurses' estimation of pain relief, it was found that patients' pain was thought to be relieved in approximately half of the patients, with no differences between control and intervention patients. Agreement between the pain relief reported by patients and that reported by district nurses about patients' pain relief was low. This study showed that district nurses of patients who received the pain education programme were hardly more actively involved in the treatment of pain compared with those in the control group.

The findings in the study suggest a significant but moderate effect of the pain education programme for district nurses.

\section{Study limitations}

However, several aspects deserve special attention as the study is hampered by some limitations.

Results showed that, despite randomization, patients in the intervention group differed at pre-test from those in the control group with respect to analgesics administered, physical functioning and cognitive functioning. Postdischarge, more patients died in the intervention group $(41 \%)$ compared with the control group $(20 \%)$. It appeared that the randomization was not fully effective in yielding balanced intervention and control groups. This high percentage of dropouts, mainly because of patients' death, might have biased the results. Consequently, the results need to be interpreted with caution. Possible bias might also be caused by district nurses and patients in the control groups being interviewed four times. As a consequence, district nurses of control group patients might have increased their care because they became aware of participating in a pain study. For patients, the attention paid to their pain might have been an intervention in itself. If so, the results might be an underestimation of the effects found, as the control group patients might have done better than less intensively studied control groups.

\section{Conclusion}

In reviewing the results of the study, district nurses play only a minor role in the treatment of cancer pain. These results are in agreement with a review article evaluating the beneficial effects of aftercare in chronic patients, in which it was found that a majority of the studies reported no clear beneficial effects (Bours et al. 1998). We also found a limited extent of communication between district nurses and other health care providers. District nurses frequently did not contact general practitioners about patients' pain problems and vice versa. In view of the huge number of patients who are dependent on a combination of health care professionals, more intense teamwork in the home situation should be stimulated. District nurses should consider the general practitioner and other caregivers as their partners to whom they can readily refer for help and advice.

Results showed that the intervention did not fully work for the district nurses as intended. Further research is needed to explore the influence of district nurses' caring and communication skills on patients' pain treatment. In order to distinguish the effects of the pain education programme for both patients and district nurses, a study should be conducted in which the effects of the pain education programme provided for patients solely are compared with the effects of the pain education programme provided solely for district nurses. Overall, it can be concluded that improving the pain knowledge in health care providers does not automatically lead to a change in their behaviour.

\section{References}

Aaronson N.K., Ahmedzai S., Bergman B., Bullinger M., Cull A., Duez N.J., Filiberti A., Flechtner H., Fleishman SB. \& de Haes JC. (1993) The European organization for research and treatment of cancer QLQ-C30: a quality-of-life instrument for use in international clinical trials in oncology. Journal of the National Cancer Institute 85, 365-376.

Agency for Health Care Policy and Research (AHCPR) (1994) Management of cancer pain. Clinical Practice Guideline. Agency for Health Care Policy and Research, Rockville, MD, USA.

American Pain Society (APS) Quality of Care Committee (1995) Quality improvement guidelines for the treatment of acute pain 
and cancer pain. Journal of the American Medical Association 274, 1874-1880.

APS (1992) Principles of analgesic use in the treatment of acute pain and chronic cancer pain: a concise guide to medical practice. American Pain Society, Skokie, IL, USA.

Au E., Loprinzi C.L., Dhodapkar M., Nelson T., Novotny P. Hammack J. \& O'Fallon J. (1994) Regular use of a verbal pain scale improves the understanding of oncology inpatient pain intensity. Journal of Clinical Oncology 12, 2751-2755.

Bours J.J.W., Ketelaars C.A.J. \& Frederiks C.A.M. (1998) Huyer Abu-Saad H, Wouters EFM. The effects of aftercare on chronic patients and frail patients when discharged from hospital: a systematic review. Journal of Advanced Nursing 27, 10761086.

Brescia F.J., Portenoy R.K., Ryan M., Krasnoff L. \& Gray G. (1992) Pain, opioid use, and survival in hospitalized patients with advanced cancer. Journal of Clinical Oncology 10, 149-155.

Carpenter J.S. \& Brockopp D. (1995) Comparison of patients' ratings and examination of nurses' responses to pain intensity rating scales. Cancer Nursing 18, 292-298.

Cleeland C.S. (1991) Pain assessment in cancer. In Effect of Cancer on Quality of Life (Osoba D. ed.), CRC Press, Boca Raton, FL, pp. 294-305.

Clotfelter C.E. (1999) The effect of an educational intervention on decreasing pain intensity in elderly people with cancer. Oncology Nursing Forum 26, 27-33.

Courtens A.M. (1993) Kenmerken van zorg en kwaliteit van leven bij patienten met kanker (Characteristics of Care and Quality of Life in Cancer Patients) [Thesis in Dutch]. University of Maastricht, Maastricht.

Dalton J.A. (1987) Education for pain management: a pilot study. Patient Education and Counseling 9, 155-165.

Dalton J.A. \& Lambe C. (1995) Tailoring treatment approaches to the individualized needs of cancer patients with pain. Cancer Nursing 18, 180-188.

De Schepper A.M., Francke A.L. \& Abu-Saad H.H. (1997) Feeling the powerlessness in relation to pain: ascribed causes and reported strategies. A qualitative study among Dutch community nurses caring for cancer patients with pain. Cancer Nursing 20, 422-429.

Desbiens N.A., Wu A.W., Yasui Y., Lynn J., Alzola C., Wenger N.S., Connors A.F., Philips R.S. \& Fulkerson W. (1998) Patient empowerment and feedback did not decrease pain in seriously ill hospitalized adults. Pain 75, 237-246.

Dorrepaal K.L. (1989) Pijn bij patienten met kanker [Thesis in Dutch] Vrije Universiteit, Universiteit.

Ferrell B.R., Ferrell B.A., Ahn C. \& Tran K. (1994) Pain management for elderly patients with cancer at home. Cancer 74, 2139-2146.

Ferrell B.R., McCaffery M. \& Rhiner M. (1992) Pain and addiction: an urgent need for change in nursing education. Journal of Pain and Symptom Management 7, 117-124.

Ferrell B.R., Rhiner M. \& Ferrell B.A. (1993) Development and implementation of a pain education program. Cancer 72, 34263432 .

Goodman C., Knight D. \& Machen I. (1998) Emphasizing terminal care as district nursing work: a helpful strategy in a purchasing environment. Journal of Advanced Nursing 28, 491-498.
Grossman S.A., Sheidler V.R., Swedeen K., Mucenski J. \& Piantadosi S. (1991) Correlation of patient and caregiver ratings of cancer pain. Journal of Pain and Symptom Management 6, 53-57.

Higginson I.J. \& Hearn J. (1997) A multicenter evaluation of cancer pain control by palliative care teams. Journal of Pain and Symptom Management 14, 29-35.

Holmes S. \& Eburn E. (1989) Patients' and nurses' perceptions of symptom distress in cancer. Journal of Advanced Nursing 14, 840-846.

Jensen M.P., Karoly P. \& Braver S. (1986) The measurement of clinical pain intensity: a comparison of six methods. Pain 27, 117-126.

Khalifa M. (1993) Inducing the quality of home health care theory through the use of grounded theory methodology. International Journal of Nursing Studies 30, 269-286.

Levin D.N., Cleeland C.S. \& Dar R. (1985) Public attitudes toward cancer pain. Cancer 56, 2337-2339.

Maloney C.H. \& Preston F. (1992) An overview of home care for patients with cancer. Oncology Nursing Forum 19, 75-80.

McCaffery M. \& Beebe A. (1989) A Pain: Clinical Manual for Nursing Practice. CV Mosby, St Louis, MO.

McGuire D.B. (1988) Measuring pain. In Instruments for Clinical Nursing (Frank-Stromborg M. ed.), Norwalk, CT, pp. 333-356.

NVBP (1990) Nederlanse Vereniging ter Bestudering van Pijn. Pijn en pijnbehandeling bij de patient met kanker. Nederlandse Vereniging ter Bestudering van Pijn, Groningen.

Philipsen H. \& Stevens F.C.J. (1997) Modernization, rationality, and continuity of care: theoretical concepts and empirical findings. Sociological Focus 30, 189-204.

Rhiner M., Ferrell B.R., Ferrell B.A. \& Grant M.M. (1993) A structured nondrug intervention program for cancer pain. Cancer Practice 1, 137-143.

Rimer B.K., Kedziera P. \& Levy M.H. (1992) The role of patient education in cancer pain control. Hospice Journal 8, 171-191.

Rimer B., Levy M., Keintz M.K., MacElwee N. \& Engstrom P.F. (1987) Improving cancer patients' pain control through education. Progress in Clinical and Biological Research 248, 123-127.

Schrijvers A.J.P. (1997) Health and health care in the Netherlands. A Critical Self-Assessment by Dutch Experts in the Medical and Health Sciences. De Tijdstroom, Utrecht.

Smeenk F.W.J.M. (1998) Transmural care of terminal cancer patients. An Evaluation Study in the Eindhoven Region: University of Maastricht.

Smets E.M.A., van Dam F.S.A.M., Dorrepaal K.L. \& Lapre F. (1989/ 90) De wijkverpleegkundige en de kankerpatiënt met pijn. Verpleegkunde 2, 85-94.

Spross J.A., McGuire D.B. \& Schmitt R.M. (1990a) Oncology Nursing Society Position Paper on Cancer Pain. Part I. Oncology Nursing Forum 17, 595-614.

Spross J.A., McGuire D.B. \& Schmitt R.M. (1990b) Oncology Nursing Society Position Paper on Cancer Pain. Part II. Oncology Nursing Forum 17, 751-760.

Van der Zee J., Kramer K., Derksen A., Kerkstra A. \& Stevens F.C.J. (1994) Community nursing in Belgium, Germany, and the Netherlands. Journal of Advanced Nursing 20, 791-801.

Ward S.E., Goldberg N., Miller-McCauley V., Mueller C., Nolan A., Pawlik-Plank D., Robbins A., Stormoen D. \& Weissman D.E. 
R. de Wit and F. van Dam

(1993) Patient-related barriers to management of cancer pain. Pain 52, 319-324.

WHO (1986) Cancer Pain Relief. World Health Organisation, Geneva, Switzerland.

WHO (1990) Cancer Pain Relief and Palliative Care. World Health Organisation, Geneva, Switzerland.
Yost L.S., McCorkle R., Buhler-Wilkerson K., Schultz D. \& Lusk E. (1993) Determinants of subsequent home health care nursing service use by hospitalized patients with cancer. Cancer 72, 3304-3312. 